\title{
Effect of MPTP on Serotonergic Neuronal Systems and Mitochondrial Complex I Activity in the Living Brain: A PET Study on Conscious Rhesus Monkeys
}

\author{
Masakatsu Kanazawa, Hiroyuki Ohba, Shingo Nishiyama, Takeharu Kakiuchi, and Hideo Tsukada \\ Central Research Laboratory, Hamamatsu Photonics K.K., Hamamatsu, Shizuoka, Japan
}

\begin{abstract}
The objective of the present PET study was to compare the effect of 1-methyl-4-phenyl-1,2,3,6-tetrahydropyridine (MPTP) on serotonergic neuronal systems and mitochondrial complex I (MC-I) activity with that of dopamine in conscious rhesus monkeys (Macaca mulatta). Methods: A Parkinson disease monkey model was prepared by repeated administration of MPTP. For the PET measurements, normal and MPTP-treated conscious monkeys received an intravenous injection of ${ }^{11} \mathrm{C}$-DASB for serotonin transporter, ${ }^{18} \mathrm{~F}$ MPPF for serotonin $1 \mathrm{~A}$ receptor, ${ }^{11} \mathrm{C}-\mathrm{PE} 2 \mathrm{I}$ for dopamine transporter, ${ }^{11} \mathrm{C}$-6MemTyr for dopamine synthesis, ${ }^{11} \mathrm{C}$-raclopride for dopamine $\mathrm{D}_{2}$ receptor, or ${ }^{18} \mathrm{~F}-\mathrm{BCPP}-\mathrm{EF}$ for $\mathrm{MC}-\mathrm{I}$. Serotonin and dopamine parameters were calculated using time-activity curves in the cerebellum as the input function. The total distribution volume of ${ }^{18} \mathrm{~F}$ BCPP-EF was assessed using Logan plot graphical analysis with metabolite-corrected plasma as the input function. Results: MPTPinduced diffuse reductions in MC-I activity were observed throughout the brain, except the cerebellum. Significant reductions in the presynaptic dopamine parameters - dopamine transporter and dopamine synthesis-were detected in the striatum and substantia nigra pars compacta of MPTP-treated monkeys, whereas no significant differences in postsynaptic dopamine $D_{2}$ receptor binding were observed. Serotonin transporter binding was reduced by MPTP not only in striatal regions but also in extrastriatal regions. In contrast, serotonin $1 \mathrm{~A}$ receptor binding was unaffected by MPTP anywhere in the brain. In the cortex, the reduction of serotonin transporter binding correlated with that of MC-I. Conclusion: The results obtained by multiparametric PET measurements in a Parkinson disease monkey model demonstrated that chronic MPTP treatment induced reductions not only in the dopaminergic system in the nigrostriatal pathway but also in serotonin transporter in the cortical and subcortical regions. These results suggest that the neurotoxicity of MPTP is not exclusive to the nigrostriatal pathway, as predicted from MC-I damage in the extrastriatal regions of the brain.
\end{abstract}

Key Words: Parkinson's disease; MPTP; serotonin; dopamine; mitochondrial complex I

J Nucl Med 2017; 58:1111-1116

DOI: 10.2967/jnumed.116.189159

\footnotetext{
Received Dec. 26, 2016; revision accepted Feb. 17, 2017.

For correspondence or reprints contact: Hideo Tsukada, Central Research Laboratory, Hamamatsu Photonics K.K, 5000 Hirakuchi, Hamakita, Shizuoka 434-8601, Japan.

E-mail: tsukada@crl.hpk.co.jp

Published online Mar. 9, 2017.

COPYRIGHT (C 2017 by the Society of Nuclear Medicine and Molecular Imaging.
}

$\mathbf{P}$

arkinson disease is the second most common neurodegenerative disease; its prevalence is $1 \%$ of the population older than $55 \mathrm{y}$, and its etiology is unknown (1). A pathologic hallmark of idiopathic Parkinson disease is the presence of Lewy bodies and neurites, which are intracytoplasmic insoluble and aggregated proteins, including $\alpha$-synuclein (2). Parkinson disease shows progressive degradation of nigrostriatal pathways, with selective loss of dopaminergic neurons in the substantia nigra pars compacta, resulting in movement disorders. These clinical symptoms of Parkinson disease are induced after $40 \%-50 \%$ of neurons in the substantia nigra pars compacta have been lost and dopamine in the striatum has been reduced to approximately $20 \%$ of normal levels (3).

Although the direct causes of this selective neurodegeneration in Parkinson disease remain unclear, mitochondrial dysfunction has emerged as a common aspect of its pathogenesis $(4,5)$. Tissues with high energy demands, such as brain, kidney, and skeletal and cardiac muscles, contain large numbers of mitochondria. In mammalian cells, the electron transport chain in mitochondria consists of 5 complexes (I-V) that produce adenosine triphosphate, and mitochondrial complex I (MC-I) (nicotinamide adenine dinucleotide [reduced form]: ubiquinone oxidoreductase, Enzyme Commission number 1.6.5.3) forms the first and rate-limiting step of overall respiratory activity and oxidative phosphorylation. In addition, MC-I is a site of reactive oxygen species production and is particularly vulnerable to oxidative damage (6). The loss of MC-I catalytic activity in the electron transport chain was reported in multiple tissues from patients exhibiting sporadic Parkinson disease $(4,5)$ with increased oxidative stress $(7)$.

Exposure to 1-methyl-4-phenyl-1,2,3,6-tetrahydropyridine (MPTP) causes a syndrome that mimics Parkinson disease symptoms and selective dopaminergic neurodegeneration in the substantia nigra pars compacta (8). 1-methyl-4-phenylpyridinium, a metabolite of MPTP by monoamine oxidase B in glial cells, selectively inhibits MC-I activity, leading to suppression of adenosine triphosphate synthesis and generation of reactive oxygen species (8). MC-I dysfunction has been identified in postmortem brain and biopsy tissue samples from Parkinson disease patients $(4,5)$. However, to our knowledge, MC-I dysfunction had not been examined noninvasively until our recent PET study on the living brains of MPTP-treated cynomolgus monkeys (Macaca fascicularis) (9).

Abnormalities in the nigrostriatal dopamine pathway may be imaged in Parkinson disease patients using PET probes for the dopamine transporter and dopamine synthesis (10). Furthermore, we recently designed a novel PET probe, 2-tert-butyl-4-chrolo-5-\{6[2-(2-18 F-fluoroethoxy)-ethoxy]-pyridin-3-ylmethoxy $\}-2 \mathrm{H}$-pyridazin3-one ( $\left.{ }^{18} \mathrm{~F}-\mathrm{BCPP}-\mathrm{EF}\right)$, for quantitative PET imaging of MC-I in vivo 
and demonstrated its capability for diagnostic, prognostic, and therapeutic monitoring of neurodegenerative diseases using monkey models of stroke with middle cerebral artery occlusion and reperfusion (11), of Alzheimer disease with amyloid- $\beta$ deposition (12), and of Parkinson disease prepared by MPTP (9), all of which are known to be related to impaired brain mitochondrial function in humans.

In our previous study on isoflurane-anesthetized cynomolgus monkeys, we observed MPTP-induced impairment of MC-I activity not only in the nigrostriatal pathway with abundant dopamine neurons (9) but also in extrastriatal nondopaminergic regions such as the cortex. Over the past 2 decades, Parkinson disease has been increasingly recognized as a disease not only with motor impairment but also with nonmotor symptoms such as depression and cognitive deficits, which are associated with changes in other monoamines (noradrenaline and serotonin) in extrastriatal regions (13). Previous findings from MPTP-treated rhesus monkeys suggested that the brain monoamine systems of dopamine, noradrenaline, and serotonin are susceptible to MPTP $(14,15)$. In addition, despite some controversy, a deficiency in serotonin was reported in the cortical regions of postmortem brains from Parkinson disease patients (16). PET imaging has revealed diffuse reductions in serotonin transporter availability throughout the brain in nondepressed Parkinson disease patients (17), as well as reductions in serotonin 1A receptor binding in both nondepressed and depressed Parkinson disease patients (18). In contrast, other studies have argued that these alterations in the serotonergic system may be partly attributable to 3,4-dihydroxy-L-phenylalanine treatment and not to primary neuropathologic alterations (19).

The present study used a Parkinson disease monkey model prepared by repeated intravenous administration of MPTP over several months (9). We evaluated ${ }^{11} \mathrm{C}$-3-amino-4-(2-dimethylaminomethylphenylsulfanyl)-benzonitrile $\left({ }^{11} \mathrm{C}-\mathrm{DASB}\right)$ availability to serotonin transporter (20) and 4-(2'-methoxyphenyl)-1-[2'-(N-2" -pyridinyl)- $p-{ }^{18} \mathrm{~F}-$ fluorobenzamido]ethylpiperazine $\left({ }^{18} \mathrm{~F}-\mathrm{MPPF}\right)$ binding to serotonin $1 \mathrm{~A}$ receptor (21) in parallel with dopaminergic parameters and MC-I activity in conscious monkeys.

\section{MATERIALS AND METHODS}

\section{Animals and Drugs}

Twelve young-adult male rhesus monkeys (Macaca mulatta: age range, 7.1-9.4 y old; weight range, $4.0-6.0 \mathrm{~kg}$ ) were maintained and handled in accordance with the recommendations of the U.S. National Institutes of Health and the guidelines of the Central Research Laboratory, Hamamatsu Photonics K.K. The experiments were approved by the Ethical Committee of the Central Research Laboratory, Hamamatsu Photonics K.K. (approval HPK-2015-15).

MR images of the monkeys were obtained with a 3.0-T scanner (Signa Excite HDxt 3.0T; GE Healthcare Japan) using a 3-dimensional spoiled gradient echo sequence under pentobarbital anesthesia.

Kryptofix 222 and $\mathrm{K}_{2} \mathrm{CO}_{3} \cdot 1.5 \mathrm{H}_{2} \mathrm{O}$ were from Merck Milipore. Anhydrous $\mathrm{CH}_{3} \mathrm{CN}$, dimethylformamide, dimethyl sulfoxide, silver trifluoromethanesulfonate, Tris(dibenzyldeneacetone)dipalladium(0), tri$o$-tolylphosphine, and MPTP were from Sigma-Aldrich Japan. Precursors of ${ }^{11} \mathrm{C}$-DASB, ${ }^{18} \mathrm{~F}-\mathrm{MPPF}, 6-{ }^{11} \mathrm{C}$-methyl- $m$-tyrosin $\left({ }^{11} \mathrm{C}-6 \mathrm{Me} m \mathrm{Tyr}\right),{ }^{11} \mathrm{C}$ raclopride, ${ }^{11} \mathrm{C}-N$-(3-iodoprop-2E-enyl)-2 $\beta$-carbomethoxy-3 $\beta$-(4-methylphenyl) nortropane $\left({ }^{11} \mathrm{C}-\mathrm{PE} 2 \mathrm{I}\right),{ }^{18} \mathrm{~F}-\mathrm{BCPP}-\mathrm{EF}$, and their corresponding standard compounds were from NARD Institute Ltd.

\section{PET Ligand Syntheses}

${ }^{11} \mathrm{C}$-DASB for serotonin transporter was labeled by ${ }^{11} \mathrm{C}-\mathrm{N}$-methylation of its nor-compound with ${ }^{11} \mathrm{C}$-methyl triflate (20). Radiochemical purity was greater than $99 \%$, and specific radioactivity was $47.6 \pm$ 11.1 GBq/ $\mu$ mol. ${ }^{18} \mathrm{~F}-\mathrm{MPPF}$ for serotonin $1 \mathrm{~A}$ receptor was prepared by nucleophilic ${ }^{18} \mathrm{~F}$-fluorination of its nitro precursor (21). Radiochemical purity was more than $99 \%$, and specific radioactivity was $90.4 \pm 25.6 \mathrm{GBq} / \mu \mathrm{mol} .{ }^{11} \mathrm{C}-\mathrm{PE} 2 \mathrm{I}$ for dopamine transporter was labeled by ${ }^{11} \mathrm{C}-O$-methylation of its nor-compound with ${ }^{11} \mathrm{C}$-methyl triflate. Radiochemical purity was greater than $98 \%$, and specific radioactivity was $117.1 \pm 42.9 \mathrm{GBq} / \mu \mathrm{mol} .{ }^{11} \mathrm{C}-6 \mathrm{Me} m \mathrm{Tyr}$ for dopamine synthesis was labeled using a rapid palladium(0)-mediated crosscoupling reaction of ${ }^{11} \mathrm{C}$-methyl iodide and its corresponding boronate precursor $(22,23)$. Radiochemical purity was greater than $99 \%$, and specific radioactivity was $71.6 \pm 37.4 \mathrm{GBq} / \mu \mathrm{mol} .{ }^{11} \mathrm{C}$-raclopride for the postsynaptic dopamine $\mathrm{D}_{2}$ receptor was labeled by ${ }^{11} \mathrm{C}-\mathrm{N}$-methylation of its nor-compound with ${ }^{11} \mathrm{C}$-methyl triflate. Radiochemical purity was greater than $98 \%$, and specific radioactivity was $65.4 \pm$ $15.8 \mathrm{GBq} / \mu \mathrm{mol} .{ }^{18} \mathrm{~F}-\mathrm{BCPP}-\mathrm{EF}$ for MC-I was prepared by nucleophilic ${ }^{18} \mathrm{~F}$-fluorination of the corresponding precursor as reported previously $(9,12,13)$. Radiochemical purity was more than $99 \%$, and specific radioactivity was $58.9 \pm 7.9 \mathrm{GBq} / \mu \mathrm{mol}$.

\section{Parkinson Disease Model}

Six of 12 young-adult male rhesus monkeys (M. mulatta) were used to prepare a Parkinson disease model according to our previous studies (9). To create bilateral striatal lesions, MPTP at doses ranging between 0.2 and $0.4 \mathrm{mg} / \mathrm{kg}$ of the free base in phosphate-buffered saline was injected intravenously over a 4-mo period until stable Parkinsonian syndrome was observed. The total doses of MPTP administered were between 8 and $14 \mathrm{mg} / \mathrm{kg}$. To avoid the potential for spontaneous recovery and direct inhibition of ${ }^{18} \mathrm{~F}-\mathrm{BCPP}-\mathrm{EF}$ binding to MC-I by MPTP, PET measurements were started at least 2 mo after the last treatment with MPTP.

\section{PET Measurements}

Six normal and 6 MPTP-treated monkeys underwent 6 PET scansusing ${ }^{11} \mathrm{C}$-DASB, ${ }^{18} \mathrm{~F}-\mathrm{MPPF},{ }^{11} \mathrm{C}$-PE2I, ${ }^{11} \mathrm{C}-6 \mathrm{Mem}$ Tyr, ${ }^{11} \mathrm{C}$-raclopride, and ${ }^{18} \mathrm{~F}-\mathrm{BCPP}-\mathrm{EF}$ - while conscious. The order of scanning with each ligand was randomized. Scanning with arterial blood sampling was performed with ${ }^{18} \mathrm{~F}$-BCPP-EF only, as reported previously $(9,12,13)$. After an overnight fast, a venous cannula for ligand injection and an arterial cannula for blood sampling were inserted into both inferior limbs under temporal anesthesia using $2.0 \%-2.5 \%$ sevoflurane $\left(1: 2 \mathrm{O}_{2}: \mathrm{N}_{2} \mathrm{O}\right)$. After the animal had completely recovered from the anesthesia, its head was rigidly fixed to the upper frame of a monkey chair using an acrylic headrestraint. The animal, sitting in the restraining chair, was placed in the gantry at a fixed position, with stereotactic coordinates aligned parallel to the orbitomeatal plane. Following a 60 -min transmission scan using a ${ }^{68} \mathrm{Ge}-{ }^{68} \mathrm{Ga}$ rotation rod source, dynamic emission scanning with each probe was performed for $91 \mathrm{~min}$ after injection using a high-resolution animal PET scanner (SHR-38000; Hamamatsu Photonics K.K.). The data were reconstructed using a dynamic row-action maximum-likelihood algorithm with a 2.0-mm gaussian postprocessing filter (24), and attenuation was corrected using the transmission scan data. Individual PET and MR images were coregistered. Volumes of interest (VOIs) were drawn manually over brain regions on the MR images, in addition to regional information from BrainMaps.org (25), and the time-activity curve of each probe was measured for kinetic analyses.

\section{PET Data Analysis}

For quantitative analysis of ${ }^{18} \mathrm{~F}-\mathrm{BCPP}-\mathrm{EF}$, arterial blood samples were obtained every $8 \mathrm{~s}$ until $64 \mathrm{~s}$ after tracer injection and then at 90 and $150 \mathrm{~s}$ and at 4, 6, 10, 20, 30, 45, 60, 75, and $90 \mathrm{~min}$. Blood samples were centrifuged to separate plasma and were weighed, and the radioactivity was measured using a $\gamma$-counter (1480 Wizard; Perkin Elmer). For metabolite analysis, ethanol was added to plasma samples (1/1 sample/ethanol $[\mathrm{v} / \mathrm{v}])$ obtained at 16,40 , and $64 \mathrm{~s}$ and then at $6,10,30,45,65,75$, and 90 min after injection, followed by centrifugation. The supernatants 


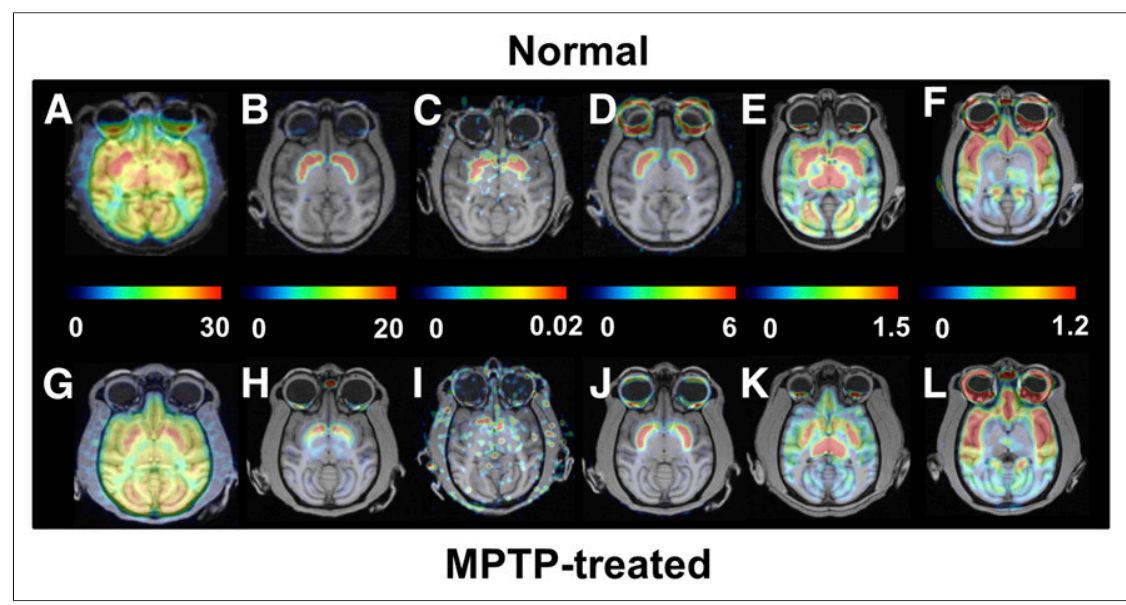

FIGURE 1. Effect of MPTP treatment on PET images of MC-I, dopamine, and serotonin in conscious monkeys. Scanning was performed for $91 \mathrm{~min}$ with ${ }^{18} \mathrm{~F}-\mathrm{BCPP}-\mathrm{EF}$ (MC-I) (A and G), ${ }^{11} \mathrm{C}$-PE2I (dopamine transporter) $(\mathrm{B}$ and $\mathrm{H}),{ }^{11} \mathrm{C}$-DASB (serotonin transporter) (E and $\mathrm{K}$ ), and ${ }^{18} \mathrm{~F}$ MPPF (serotonin $1 A$ receptor) ( $F$ and $L$ ) and for 60 min with ${ }^{11} \mathrm{C}-6 \mathrm{Mem}$ Tyr (dopamine synthesis) $(\mathrm{C}$ and $\mathrm{I}$ ) and ${ }^{11} \mathrm{C}$-raclopride (dopamine $\mathrm{D}_{2}$ receptor) ( $\mathrm{D}$ and $\mathrm{J}$ ). $\mathrm{V}_{\mathrm{T}}$ images of ${ }^{18} \mathrm{~F}$-BCPP-EF were created using Logan graphical plot analysis with metabolite-corrected plasma input function. $\mathrm{BP}_{\mathrm{ND}}$ images of ${ }^{11} \mathrm{C}$-PE2I, ${ }^{11} \mathrm{C}$-raclopride, ${ }^{11} \mathrm{C}$-DASB, and ${ }^{18} \mathrm{~F}-\mathrm{MPPF}$ and multiple-time graphical analysis $K_{i}$ images of ${ }^{11} \mathrm{C}$-6MemTyr were created using the corresponding time-activity curves in cerebellum as input function.

were developed using thin-layer chromatography plates (silica gel 60 F254; Merck) with ethyl acetate as the mobile phase. The ratio of unmetabolized fraction was assessed using a phosphor imaging plate and a bioimaging analyzer (FLA-7000; Fuji Film). The arterial input function

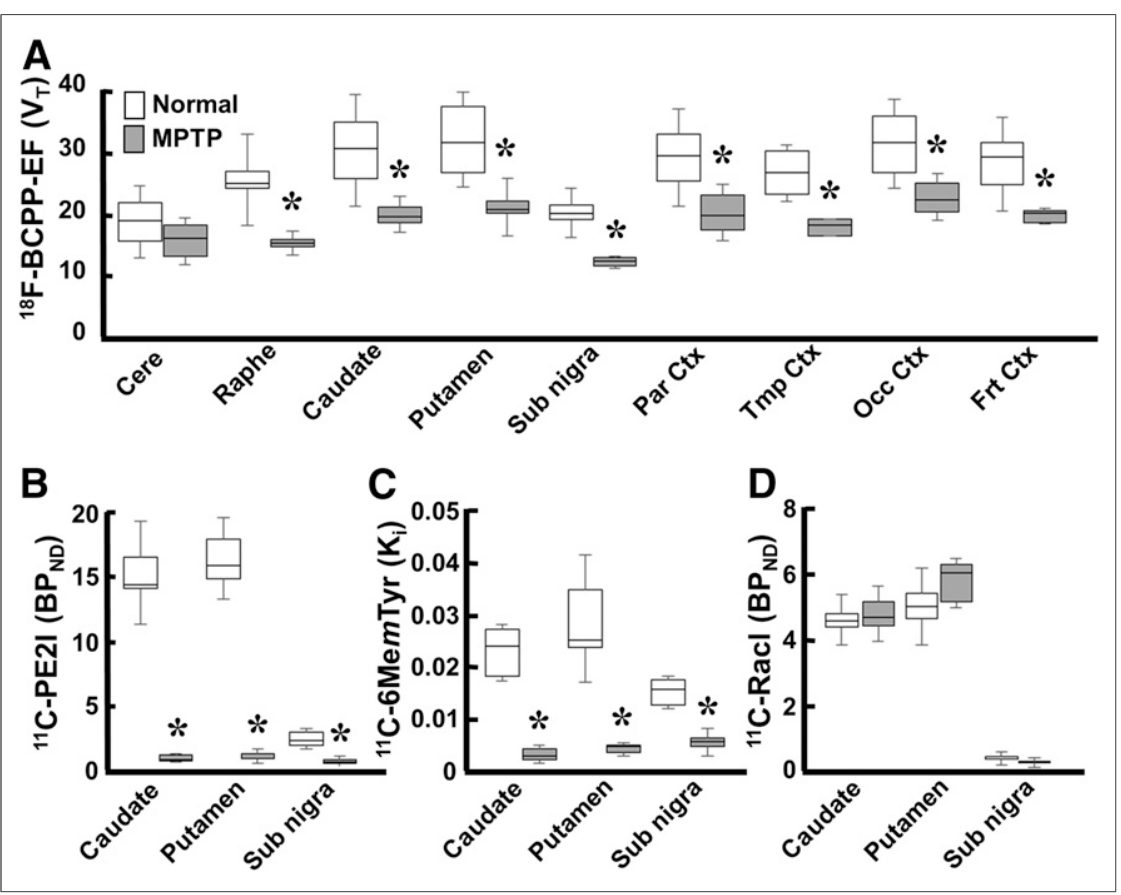

FIGURE 2. Effect of MPTP treatment on MC-I and pre- and postsynaptic dopamine parameters in conscious monkeys. (A) Binding of ${ }^{18} \mathrm{~F}-\mathrm{BCPP}-\mathrm{EF}$ to $\mathrm{MC}-\mathrm{I}$ was calculated using Logan graphical plot analysis. (B and D) ${ }^{11} \mathrm{C}$-PE2I availability to dopamine transporter $(\mathrm{B})$ and ${ }^{11} \mathrm{C}$-raclopride binding to dopamine $\mathrm{D}_{2}$ receptor (D) were calculated using $B P_{\mathrm{ND}}$ analysis. (C) ${ }^{11} \mathrm{C}-6 \mathrm{MemTyr}$ for dopamine synthesis was calculated using multiple-time graphical analysis. Data are expressed as box plots showing median, minimum, and maximum. ${ }^{\star} P<0.05$ vs. normal. for unmetabolized ${ }^{18} \mathrm{~F}-\mathrm{BCPP}-\mathrm{EF}$ was calculated using data obtained by a correction of the ratio of unmetabolized fraction to total radioactivity.

The kinetics of ${ }^{18} \mathrm{~F}-\mathrm{BCPP}-\mathrm{EF}$ were analyzed using Logan graphical analysis (26) with PMOD software (PMOD Technologies Ltd.), as reported previously (12,13). PMOD software was also used to calculate the nondisplaceable binding potential $\left(\mathrm{BP}_{\mathrm{ND}}\right)$ of ${ }^{11} \mathrm{C}$ DASB, ${ }^{18} \mathrm{~F}-\mathrm{MPPF}$, and ${ }^{11} \mathrm{C}-\mathrm{PE} 2 \mathrm{I}$ via a simplified reference tissue model (27), with the time-activity curve in the cerebellum applied as the indirect input function, as well as to perform multiple-time graphical analysis of ${ }^{11} \mathrm{C}-6 \mathrm{Me} m \mathrm{Tyr}(9,22,23,28,29)$, with the time-activity curve in the occipital cortex applied as the input function (30).

Correlation analysis was performed of the degree of MPTP-induced reduction in $\mathrm{BP}_{\mathrm{ND}}$ for ${ }^{11} \mathrm{C}-\mathrm{PE} 2 \mathrm{I}$ in nigrostriatal regions (caudate, putamen, and substantia nigra pars compacta), the degree of MPTP-induced reduction in inhibition constant $\left(K_{i}\right)$ for ${ }^{11} \mathrm{C}-6 \mathrm{Me} m \mathrm{Tyr}$ in nigrostriatal regions, and the degree of MPTP-induced reduction in $\mathrm{BP}_{\mathrm{ND}}$ for ${ }^{11} \mathrm{C}$-DASB in nigrostriatal and cortical regions (frontal, occipital, temporal, and parietal) against the degree of MPTP-induced reduction in distribution volume $\left(\mathrm{V}_{\mathrm{T}}\right)$ for ${ }^{18} \mathrm{~F}-\mathrm{BCPP}-\mathrm{EF}$. The same VOIs, determined with the aid of individual MR images, were set on the parametric PET images of normal and MPTP-treated monkeys to obtain $K_{i}$ for ${ }^{11} \mathrm{C}$ $6 \mathrm{Me} m$ Tyr, $\mathrm{BP}_{\mathrm{ND}}$ for ${ }^{11} \mathrm{C}-\mathrm{DASB}$, and $\mathrm{V}_{\mathrm{T}}$ for ${ }^{18} \mathrm{~F}-\mathrm{BCPP}-\mathrm{EF}$. Then, averaged $K_{i}, \mathrm{BP}_{\mathrm{ND}}$, and $\mathrm{V}_{\mathrm{T}}$ for each VOI of 6 normal monkeys were calculated and subtracted from each VOI of individual MPTP-treated monkeys to determine the degree of MPTP-induced reduction as $\Delta \mathrm{BP}_{\mathrm{ND}}$ for ${ }^{11} \mathrm{C}-\mathrm{PE} 2 \mathrm{I}, \Delta K_{i}$ for ${ }^{11} \mathrm{C}-6 \mathrm{Mem}$ Tyr, $\Delta \mathrm{BP}_{\mathrm{ND}}$ for ${ }^{11} \mathrm{C}-\mathrm{DASB}$, and $\Delta \mathrm{V}_{\mathrm{T}}$ for ${ }^{18} \mathrm{~F}-$ BCPP-EF. $\Delta K_{i}$ and $\Delta \mathrm{BP}_{\mathrm{ND}}$ in each VOI were plotted against the corresponding $\Delta \mathrm{V}_{\mathrm{T}}$ as reported previously (9).

\section{Statistical Analysis}

Results are expressed as mean \pm SD. Comparisons between conditions were made by unpaired 2-tailed Student $t$ testing, and correlations were tested by a single regression analysis using KaleidaGraph (Synergy Software). A probability level of less than $5 \%(P<0.05)$ was considered to indicate significance.

\section{RESULTS}

In MPTP-treated monkeys, $\mathrm{V}_{\mathrm{T}}$ for ${ }^{18} \mathrm{~F}$ BCPP-EF (Figs. $1 \mathrm{G}$ and 2A) showed significant reductions to $68.9 \%, 72.3 \%, 67.7 \%$, $66.4 \%, 68.1 \%, 65.2 \%, 60.9 \%$, and $62.7 \%$ of normal levels (Figs. 1A and 2A) in the frontal, occipital, temporal, and parietal cortices; the putamen; the caudate; the raphe nucleus; and the substantia nigra pars compacta, respectively, and no significant decrease in the cerebellum. 


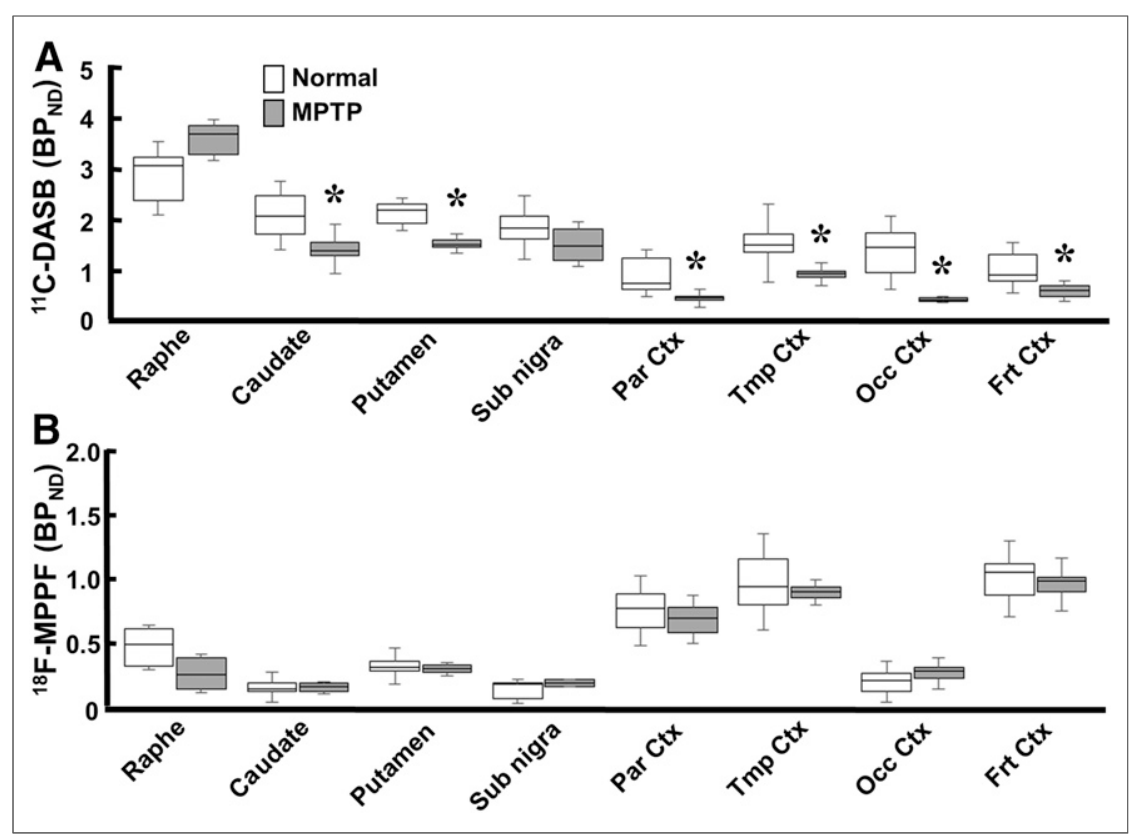

FIGURE 3. Effect of MPTP treatment on serotonin transporter and serotonin $1 \mathrm{~A}$ receptor in conscious monkeys. ${ }^{11} \mathrm{C}$-DASB availability to serotonin transporter (A) and ${ }^{18} \mathrm{~F}-\mathrm{MPPF}$ binding to serotonin $1 \mathrm{~A}$ receptor $(\mathrm{B})$ were measured using $\mathrm{BP}_{\mathrm{ND}}$ analysis. Data are expressed as box plot showing median, minimum, and maximum. ${ }^{\star} P<0.05$ vs. normal.

No significant changes in ${ }^{11} \mathrm{C}$-raclopride binding to dopamine $\mathrm{D}_{2}$ receptor were observed in the striatum or substantia nigra pars compacta between MPTP-treated monkeys (Figs. 1J and 2D) and normal animals (Figs. 1D and 2D). When dopamine transporter availability, a presynaptic parameter, was assessed with ${ }^{11} \mathrm{C}-\mathrm{PE} 2 \mathrm{I}$, availability in the caudate, putamen, and substantia nigra pars compacta was found to be significantly lower in MPTP monkeys $(4.0 \%, 4.9 \%$, and $18.6 \%$ of the normal level) (Figs. 1H and 2B) than in normal animals (Figs. 1B and $2 \mathrm{~B}$ ). When dopamine synthesis, another presynaptic parameter, was assessed using ${ }^{11} \mathrm{C}-6 \mathrm{Mem} \mathrm{Tyr}$, synthesis in the striatum and substantia nigra pars compacta was also found to be markedly lower in MPTP monkeys $(13.6 \%, 12.3 \%$, and $41.1 \%$ of the normal level) (Figs. 1I and 2C) than in normal animals (Figs. 1C and 2C).

Quantitative analysis of ${ }^{11} \mathrm{C}$-DASB revealed that MPTP-treated monkeys had reduced serotonin transporter availability in all brain regions except the raphe nucleus (Figs. $1 \mathrm{~K}$ and $3 \mathrm{~A}$ ). The reduction was greatest in the occipital cortex (19.7\% of normal); was lower in the frontal, parietal, and temporal cortices $(50.0 \%, 40.7 \%$, and $51.6 \%$ of normal, respectively); was lower still in the caudate $(60.3 \%$ of normal); and was least in the putamen and substantia nigra pars compacta $(66.0 \%$ and $67.7 \%$ of normal, respectively) (Figs. 1E and $3 \mathrm{~A})$. In contrast, binding of ${ }^{18} \mathrm{~F}-\mathrm{MPPF}$ to serotonin $1 \mathrm{~A}$ receptor did not significantly change in any brain region of MPTP monkeys (Figs. $1 \mathrm{~L}$ and $3 \mathrm{~B}$ ) compared with normal animals (Figs. 1L and 3B).

As shown in Figure 4, when $\Delta \mathrm{BP}_{\mathrm{ND}}$ for ${ }^{11} \mathrm{C}$-PE2I, $\Delta K_{i}$ for ${ }^{11} \mathrm{C}$ $6 \mathrm{Me} m \mathrm{Ty}$, and $\Delta \mathrm{BP}_{\mathrm{ND}}$ for ${ }^{11} \mathrm{C}$-DASB in each VOI were plotted against the corresponding $\Delta \mathrm{V}_{\mathrm{T}}$ for ${ }^{18} \mathrm{~F}-\mathrm{BCPP}-\mathrm{EF}$, significant positive correlations were observed between $\Delta \mathrm{BP}_{\mathrm{ND}}$ for ${ }^{11} \mathrm{C}$-PE2I and $\Delta \mathrm{V}_{\mathrm{T}}$ for ${ }^{18} \mathrm{~F}-\mathrm{BCPP}-\mathrm{EF}\left(r^{2}=0.521, P<0.01\right)$ (Fig. 4A), between $\Delta K_{i}$ for ${ }^{11} \mathrm{C}-6 \mathrm{Me} m \mathrm{Tyr}$ and $\Delta \mathrm{V}_{\mathrm{T}}$ for ${ }^{18} \mathrm{~F}-\mathrm{BCPP}-\mathrm{EF}$ in nigrostriatal regions $\left(r^{2}=0.537, P<0.01\right)$ (Fig. $\left.4 \mathrm{~B}\right)$, and between $\Delta \mathrm{BP}_{\mathrm{ND}}$ for ${ }^{11} \mathrm{C}$-DASB and $\Delta \mathrm{V}_{\mathrm{T}}$ for ${ }^{18} \mathrm{~F}-\mathrm{BCPP}-\mathrm{EF}$ in cortical regions $\left(r^{2}=\right.$ $0.403, P<0.01$ ) (Fig. 4D). In contrast, no significant correlation between $\triangle \mathrm{BP}_{\mathrm{ND}}$ for ${ }^{11} \mathrm{C}$-DASB and $\Delta \mathrm{V}_{\mathrm{T}}$ for ${ }^{18} \mathrm{~F}$-BCPP-EF was detected in nigrostriatal regions (Fig. 4C).

\section{DISCUSSION}

The present study demonstrated that MPTP-induced damage detected as MC-I impairment was not exclusive to the dopaminergic nigrostriatal pathway and that damage in the extrastriatal regions was partly attributable to serotonergic neuronal damage.

Administration of MPTP causes slow, progressive loss of dopamine neurons over several months, and the decrease in nigrostriatal dopamine levels is considered responsible for the motor symptoms of MPTPtreated monkeys. Impaired electron transport and oxidative phosphorylation due to an MC-I deficiency may account for neuronal cell death in Parkinson disease. Alternatively, the MC-I deficiency in Parkinson disease may be secondary to mitochondrial damage due to oxidative stress. MC-I, a site at which reactive oxygen species are produced, is particularly vulnerable to oxidative damage (6). We previously demonstrated the potential of ${ }^{18} \mathrm{~F}-\mathrm{BCPP}-\mathrm{EF}$ to detect MPTP-induced impairment of MC-I activity, which strongly correlated with damage in presynaptic dopamine neurons assessed as dopamine transporter availability or dopamine synthesis in a Parkinson cynomolgus model under isoflurane anesthesia (9).
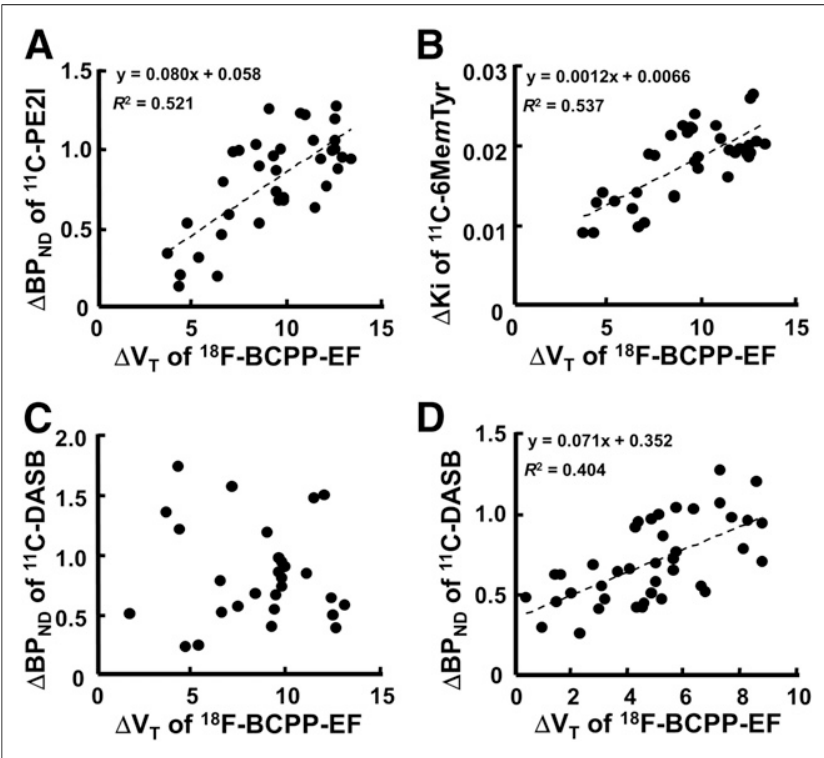

FIGURE 4. Effect of MPTP-induced MC-I impairment on dopamine transporter availability (A), dopamine synthesis in nigrostriatal region (B), and serotonin transporter in nigrostriatal (C) and cortical regions (D) of conscious monkeys. Averaged $\mathrm{BP}_{\mathrm{ND}}$ for ${ }^{11} \mathrm{C}-\mathrm{PE} 2 \mathrm{l}, K_{i}$ for ${ }^{11} \mathrm{C}-6 \mathrm{MemTyr}, \mathrm{BP}_{\mathrm{ND}}$ for ${ }^{11} \mathrm{C}-$ $\mathrm{DASB}$, and $\mathrm{V}_{\mathrm{T}}$ for ${ }^{18} \mathrm{~F}-\mathrm{BCPP}-\mathrm{EF}$ in each $\mathrm{VOI}$ of normal monkeys were calculated and subtracted from each VOI of individual MPTP-treated monkeys to determine degree of MPTP-induced reduction. Then, $\Delta K_{i}$ or $\Delta \mathrm{BP}_{\mathrm{ND}}$ in each VOI was plotted against the corresponding $\Delta \mathrm{V}_{\mathrm{T}}$. 
Measurement of MC-I activity using ${ }^{18} \mathrm{~F}-\mathrm{BCPP}-\mathrm{EF}$ is not affected by isoflurane anesthesia (12). Dopamine $\mathrm{D}_{2}$ receptor binding (31) and dopamine transporter availability (32), however, have been reported to be affected-thus our intention to assess all PET parameters in conscious animals in the present study. The present study also confirmed that MPTP treatment induced an impairment of MC-I activity as measured using ${ }^{18} \mathrm{~F}-\mathrm{BCPP}-\mathrm{EF}$, and this finding correlated well with reduced dopamine transporter availability as measured using ${ }^{11} \mathrm{C}$-PE2I and with presynaptic dopamine synthesis as measured using ${ }^{11} \mathrm{C}-6 \mathrm{Mem}$ Tyr $(9,22,23)$.

Our preliminary observations (9) suggested that impairment of MC-I activity is also induced in the nondopaminergic brain regions of MPTP-treated cynomolgus monkeys, and the present study with rhesus monkeys confirmed that the toxic effect of MPTP occurred not only in the dopamine-rich regions of the substantia nigra pars compacta and striatum but also in brain regions with very few dopaminergic neurons. Thus, in this conscious monkey model, ${ }^{18} \mathrm{~F}-\mathrm{BCPP}-\mathrm{EF}$ detects MPTP-induced impairment of MC-I activity in extrastriatal brain regions such as the cortex, mid brain, and limbic system, and this impairment is associated with decreased binding of ${ }^{11} \mathrm{C}$-DASB to serotonin transporter. This result is inconsistent with previous findings showing, in postmortem Parkinson disease brain, that MPTP induces neuronal damage (8) and MC-I deficiency (33) exclusively in dopaminergic neurons in the nigrostriatal regions.

Two transport systems, uptake 1 and uptake 2, are responsible for terminating monoaminergic neurotransmission by clearance from extracellular space. Uptake 1 is an $\mathrm{Na}^{+}$- and $\mathrm{Cl}^{-}$-dependent high-affinity transporter system and includes dopamine transporter, serotonin transporter, and norepinephrine transporter. These are expressed on the nerve endings of monoaminergic neurons, and their clearance is from the synaptic cleft. Uptake 2 was originally characterized as an $\mathrm{Na}^{+}-$and $\mathrm{Cl}^{-}$-independent lowaffinity, high-capacity transport system in peripheral organs; however, this transporter was suggested to be involved in monoamine signaling pathways in the brain $(34,35)$. Uptake 2 consists of multiple organic cation transporters; in particular, organic cation transporters are prominent not only for endogenous monoamines but also for prototypical organic cations such as 1-methyl-4phenylpyridinium $(35,36)$. Thus, it is not difficult to imagine that 1-methyl-4-phenylpyridinium can be gradually transported into monoaminergic cells, including serotonergic neurons, through the uptake 2 system during repeated MPTP administration. 1-methyl-4-phenylpyridinium enters mitochondria and selectively binds to and inhibits the MC-I contained within all kinds of monoaminergic cells, leading to inhibition of adenosine triphosphate synthesis and of reactive oxygen species production (33). A small loss $(\sim 25 \%)$ in MC-I activity is sufficient to decrease adenosine triphosphate synthesis in neuronal cells, resulting in neurodegenerative damage in monoaminergic neurons. In fact, previous studies on MPTP-treated rhesus monkeys showed that the brain monoamine systems for not only dopamine but also noradrenaline and serotonin are susceptible to MPTP (14).

There is increasing evidence that in addition to causing motor symptoms, Parkinson disease is associated with nonmotor symptoms such as depression and cognitive deficits, which may be related to changes in other monoamines (noradrenaline and serotonin) in extrastriatal regions (13). Lewy body and neurite deposition occurs within the raphe nucleus, which contains the serotoninergic neurons of the caudal brain stem (33), before it occurs in the midbrain, which contains dopaminergic neurons $(37,38)$. Decreases in serotonin concentration have been reported postmortem in the cortical brain regions of Parkinson disease patients (15). PET imaging of nondepressed Parkinson disease patients has revealed diffuse reductions in ${ }^{11} \mathrm{C}$-DASB binding to serotonin transporter throughout the brain, suggesting a diminished density of serotonergic fibers $(16,17)$. In contrast, other studies have indicated an increase in ${ }^{11} \mathrm{C}$-DASB binding to serotonin transporter in the limbic structures of depressed Parkinson disease patients $(39,40)$, suggesting compensatory upregulation of serotonin transporter leading to a reduction in serotonergic neurotransmission.

Although the present study demonstrated no significant MPTPinduced changes in ${ }^{18} \mathrm{~F}-\mathrm{MPPF}$ binding to serotonin $1 \mathrm{~A}$ receptor in monkeys, clinical PET research has reported significantly weaker serotonin 1A receptor binding in nondepressed and depressed Parkinson disease patients than in controls (18). Because some studies have refutably demonstrated that these alterations in the serotonergic system are partly attributable to 3,4-dihydroxy-L-phenylalanine treatment (19), these controversial findings do not appear to reflect the primary neuropathologic alterations in Parkinson disease.

\section{CONCLUSION}

The present results suggest that ${ }^{18} \mathrm{~F}-\mathrm{BCPP}-\mathrm{EF}$ has the potential to become a useful PET probe for quantitative imaging of MPTPinduced degeneration in not only dopaminergic but also nondopaminergic neurons, as shown by impaired MC-I activity in conscious monkeys.

\section{DISCLOSURE}

No potential conflict of interest relevant to this article was reported.

\section{ACKNOWLEDGMENTS}

We gratefully acknowledge Norihiro Harada, Dai Fukumoto, and Aiko Iwazaki for their technical assistance.

\section{REFERENCES}

1. Lees AJ, Hardy J, Revesz T. Parkinson's disease. Lancet. 2009;373:2055-2066.

2. Spillantini MG, Schmidt ML, Lee VM, Trojanowski JQ, Jakes R, Goedert M. Alpha-synuclein in Lewy bodies. Nature. 1997;388:839-840.

3. Kish SJ, Shannak K, Hornykiewicz O. Uneven pattern of dopamine loss in the striatum of patients with idiopathic Parkinson's disease: pathophysiologic and clinical implications. N Engl J Med. 1988;318:876-880.

4. Schapira AHV, Cooper JM, Dexter D, Clark JB, Jenner P, Marsden CD. Mitochondrial complex I deficiency in Parkinson's disease. J Neurochem. 1990;54:823-827.

5. Swerdlow RH, Parks JK, Miller SW, et al. Origin and functional consequences of the complex I defect in Parkinson's disease. Ann Neurol. 1996;40:663-671.

6. Robinson BH. Human complex I deficiency: clinical spectrum and involvement of oxygen free radicals in the pathogenicity of the defect. Biochim Biophys Acta. 1998; 1364:271-286.

7. Keeney PM, Xie J, Capaldi RA, Bennett JP Jr. Parkinson's disease brain mitochondrial complex I has oxidatively damaged subunits and is functionally impaired and misassembled. J Neurosci. 2006;26:5256-5264.

8. Burns RS, Chiueh CC, Markey SP, Ebert MH, Jacobowitz DM, Kopin IJ. A primate model of parkinsonism: selective destruction of dopaminergic neurons in the pars compacta of the substantia nigra by MPTP. Proc Natl Acad Sci USA. 1983;80:4546-4550.

9. Tsukada H, Kanazawa M, Ohba H, Nishiyama S, Harada N, Kakiuchi T. PET imaging of mitochondrial complex I with ${ }^{18} \mathrm{~F}-\mathrm{BCPP}-\mathrm{EF}$ in brain of Parkinson's disease model monkey. J Nucl Med. 2016;57:950-953.

10. Brooks DJ. Imaging approaches to Parkinson disease. J Nucl Med. 2010;51:596-609.

11. Tsukada H, Ohba H, Nishiyama S, Kanazawa M, Kakiuchi T, Harada N. PET imaging of ischemia-induced impairment of mitochondrial complex I function in monkey brain. J Cereb Blood Flow Metab. 2014;34:708-714. 
12. Tsukada H, Nishiyama S, Ohba H, Kanazawa M, Kakiuchi T, Harada N. Comparing amyloid- $\beta$ deposition, neuroinflammation, glucose metabolism, and mitochondrial complex I activity in brain: a PET study in aged monkeys. Eur J Nucl Med Mol Imaging. 2014;41:2127-2136.

13. Chaudhuri KR, Healy DG, Schapira AH. Non-motor symptoms of Parkinson's disease: diagnosis and management. Lancet Neurol. 2006;5:235-245.

14. Pifl C, Schingnitz G, Hornykiewicz O. Effect of MPTP on the regional distribution of brain monoamines in the rhesus monkey. Neuroscience. 1991;44:591605.

15. Scatton B, Javoy-Agid F, Rouquier L, Dubois B, Agid Y. Reduction of cortical dopamine, noradrenaline, serotonin and their metabolites in Parkinson's disease. Brain Res. 1983;275:321-328.

16. Guttman M, Boileau I, Warsh J, et al. Brain serotonin transporter binding in nondepressed patients with Parkinson's disease. Eur J Neurol. 2007;14:523-528.

17. Albin RL, Koeppe RA, Bohnen NI, Wernette K, Kilbourn MA, Frey KA. Spared caudal brainstem SERT binding in early Parkinson's disease. J Cereb Blood Flow Metab. 2008;28:441-444.

18. Ballanger B, Klinger H, Eche J, et al. Role of serotonergic 1A receptor dysfunction in depression associated with Parkinson's disease. Mov Disord. 2012;27:84-89.

19. Boulet S, Mounayar S, Poupard A, et al. Behavioral recovery in MPTP-treated monkeys: neurochemical mechanisms studied by intrastriatal microdialysis. $J$ Neurosci. 2008;28:9575-9584.

20. Wilson AA, Ginovart N, Schmidt M, Meyer JH, Threlkeld PG, Houle S. Novel radiotracers for imaging the serotonin transporter by positron emission tomography: synthesis, radiosynthesis, and in vitro and ex vivo evaluation of ${ }^{11} \mathrm{C}$ labeled 2-(phenylthio)araalkylamines. J Med Chem. 2000;43:3103-3110.

21. Le Bars D, Lemaire C, Ginovart N, et al. High-yield radiosynthesis and preliminary in vivo evaluation of $\mathrm{p}-\left[{ }^{18} \mathrm{~F}\right] \mathrm{MPPF}$, a fluoro analog of WAY-100635. Nucl Med Biol. 1998;25:343-350.

22. Kanazawa M, Ohba H, Iwazaki A, Kakiuchi T, Tsukada H. Synthesis of $6{ }^{-1} \mathrm{C}-$ methyl-m-tyrosine $\left({ }^{11} \mathrm{C}-6 \mathrm{Me} m \mathrm{Tyr}\right)$ for dopamine synthesis imaging in living brain using PET. Bioorg Med Chem. 2015;23:729-734.

23. Kanazawa M, Ohba H, Harada N, Kakiuchi T, Muramatsu S, Tsukada H. Evaluation of $6-{ }^{11} \mathrm{C}$-methyl- $m$-tyrosine as a PET probe for presynaptic dopaminergic activity: a comparison PET study with $\beta-{ }^{11} \mathrm{C}$-L-DOPA and ${ }^{18} \mathrm{~F}$-FDOPA in Parkinson's disease monkeys. J Nucl Med. 2016;57:303-308.

24. Tanaka E, Kudo H. Optimal relaxation parameters of DRAMA (dynamic RAMLA) aiming at one-pass image reconstruction for 3D-PET. Phys Med Biol. 2010;55:2917-2939.

25. Jones EG, Stone JM, Karten HJ. High-resolution digital brain atlases: a Hubble telescope for the brain. Ann N Y Acad Sci. 2011;1225(suppl 1):E147-E159.
26. Logan J, Volkow ND, Fowler JS, et al. Effects of blood flow on $\left[{ }^{11} \mathrm{C}\right]$ raclopride binding in the brain: model simulations and kinetic analysis of PET data. J Cereb Blood Flow Metab. 1994;14:995-1010.

27. Innis RB, Cunningham VJ, Delforge J, et al. Consensus nomenclature for in vivo imaging of reversibly binding radioligands. J Cereb Blood Flow Metab. 2007; 27:1533-1539.

28. Patlak CS, Blasberg RG. Graphical evaluation of blood-to-brain transfer constants from multiple-time uptake data: generalizations. J Cereb Blood Flow Metab. 1985;5:584-590.

29. Gjedde A, Reith J, Dyve S, et al. Dopa decarboxylase activity of the living human brain. Proc Natl Acad Sci USA. 1991;88:2721-2725.

30. Eberling JL, Bankiewicz KS, O'Neil JP, Jagust WJ. PET 6- $\left[{ }^{18} \mathrm{~F}\right]$ fluoro-L-mtyrosine studies of dopaminergic function in human and nonhuman primates. Front Hum Neurosci. 2008;1:9.

31. Tsukada H, Miyasato K, Kakiuchi T, Nishiyama S, Harada N, Domino EF. Comparative effects of methamphetamine and nicotine on the striatal $\left[{ }^{11} \mathrm{C}\right]$ raclopride binding in unanesthetized monkeys. Synapse. 2002;45:207-212.

32. Tsukada H, Nishiyama S, Kakiuchi $T$, et al. Isoflurane anesthesia enhances the inhibitory effects of cocaine and GBR12909 on dopamine transporter: PET studies in combination with microdialysis in the monkey brain. Brain Res. 1999;849:85-96.

33. Orth M, Schapira AHV. Mitochondrial involvement in Parkinson's disease. Neurochem Int. 2002;40:533-541.

34. Wu X, Kekuda R, Huang W, et al. Identity of the organic cation transporter OCT3 as the extraneuronal monoamine transporter (uptake2) and evidence for the expression of the transporter in the brain. J Biol Chem. 1998;273:3277632786.

35. Engel K, Zhou M, Wang J. Identification and characterization of a novel monoamine transporter in the human brain. J Biol Chem. 2004;279:50042-50049.

36. Koepsell H, Lips K, Volk C. Polyspecific organic cation transporters: structure, function, physiological roles, and biopharmaceutical implications. Pharm Res. 2007; $24: 1227-1251$

37. Hornung J-P. The human raphe system and the serotonergic system. J Chem Neuroanat. 2003;26:331-343.

38. Braak H, Del Tredici K, Rub U, de Vos RAI, Jansen Steur ENH, Braak E. Staging of brain pathology related to sporadic Parkinson's disease. Neurobiol Aging. 2003;24:197-211.

39. Boileau I, Warsh JJ, Guttman M, et al. Elevated serotonin transporter binding in depressed patients with Parkinson's disease: a preliminary PET study with $\left[{ }^{11}\right.$ C]DASB. Mov Disord. 2008;23:1776-1780.

40. Politis M, Wu K, Loane C, et al. Depressive symptoms in PD correlate with higher 5-HTT binding in raphe and limbic structures. Neurology. 2010;75:19201927. 